\title{
Development and standardization of indigenized emotional intelligence scale
}

\begin{abstract}
The coetaneous study was effectuated to develop and validate a chthonic self-report measure of Emotional Intelligence. With a newfangled aim to develop a reliable and valid measurement instrument of emotional intelligence based on mixed model, the mixed model of emotional intelligence and literature on it were investigated, and then an item pool with 60 items was developed. Fourteen experts of emotional intelligence examined 72 items. In order to make the expert's judgments standardized, Lawshe Content Validity Ratio was used. As a result of the ratio analysis, 12 items were discarded from initial draft of the scale. Data were collected from a sample of 1664 individuals including 874 men and 790 women recruited from different cities of India for the exploratory factor analysis whose results indicated the scale includes unidimensionality. Results indicated that the scale is reliable and valid instrument in measuring emotional intelligence. Construct validity was supplemented by finding its relationship with peer rating and correlation was found to be moderately positive. The Scale is a promising measure with good items homogeneity, internal consistency and a meaningful pattern of validity.
\end{abstract}

Keywords: emotional intelligence, validity, reliability, standardization, explain success, educationalists, skills, environmental pressures, adaptability, stress management, motivation, general mood, intelligence scale
Volume 2 Issue 6 - 2018

\author{
Shruti Marwaha \\ Research Scholar, Department of Anthropology, Panjab \\ University, Chandigarh, India
}

\begin{abstract}
Correspondence: Shruti Marwaha, Research Scholar, Department of Anthropology, Panjab University, Chandigarh, India, Email developmentrasearch04@gmail.com
\end{abstract}

Received: June 26, 2018| Published: November 16, 2018

\section{Introduction}

Emotional intelligence (EI) has offered new paradigm for educationalists that try to explain success and adjustment to environment. Concept of the EI first was developed by Mayer et al., ${ }^{1}$ However Goleman ${ }^{2}$ made it popularized and publicized. Large body of the research has proved that EI has positive impact on educational attainment, social adjustment, happiness, and academic self-efficacy. ${ }^{3-10}$ however there are disagreements and conflicts about definitions, qualities, and conceptualization of the EI. Those disagreements have stemmed from measurement paradigm of the EI. ${ }^{11}$ There are mainly three streams in EI: ability model, mixed models, and trait model. ${ }^{11}$ Salovey and Mayer ${ }^{1}$ developers of the ability model, described as that EI is the capacity to recognize and manage emotions in ourselves and in others, process emotional information. In the ability model, EI is assumed as capability of carrying out accurate emotional reasoning. ${ }^{1}$ The ability model constructs emotion and reasoning under same phenomena. The model consists of four abilities (those accurately perceiving emotion, using emotion to facilitate thought, understanding emotion, and managing emotion). ${ }^{12}$ In the ability model, there is a close interaction among the skills. For instance a child cannot be efficacious without perceiving emotion in herself. ${ }^{1}$ Mixed models, another approach to the EI, views the EI as an integration of skills and qualities such as personality and motivational dispositions that are necessary to use the EI in real life. Proponents of the $\mathrm{EI}^{13}$ with a wide range of skills and competencies rather than to define it as a single construct. In other words, EI is explained through broad definitions such as noncognitive capability, competency, skill or emotionally intelligent behavior, and dispositions of personality. ${ }^{13}$ Bar-On ${ }^{8}$ describes the EI as cluster of noncognitive skills that are necessary to cope with effectively environmental demands. Bar$\mathrm{On}^{6}$ suggests that the EI is one of the main determinants of effective human behavior. Bar-On (1997) developed EI model consisting of intrapersonal capacity, interpersonal skills, adaptability, stress management, motivation, and general mood.

The Bar-On model claims that the EI is a joint of interrelated competencies, skills, and facilitators that influence how effectively an individual understands and expresses him, recognize emotions in others, has good relationships with others, and fulfill social and environmental pressures. ${ }^{6}$ Goleman ${ }^{2}$ model is another model in the mixed models. It has five sub-dimensions as self-awareness, self- management, empathy, motivation and social skills. Trait model developed by Petrides et al., ${ }^{13}$ is another approach to the EI. Trait EI is a constellation of self-perception of the lower level of personality constructs. Trait EI includes 5 facets as adaptability, low impulsiveness, self-esteem, self-motivation, stress management, trait happiness, trait optimism, assertiveness, relationship skills, social competence, trait empathy, emotional expression, emotional management, emotional perception, and emotional regulation. ${ }^{13}$ The difference between the EI models stems from way of measurement and assessment of the EI. ${ }^{11}$ The ability model deals with measurement and assessment of the EI in the same way as traditional intelligence standard test measures and assesses. The ability model measures and assesses through performance-based test because of the fact that the ability model deals with the EI as a single construct and standard intelligence type. According to the ability model, the EI is the capacity in reasoning with emotions. Therefore, the EI can be measured and quantified through the way in which standard traditional intelligence is measured. Participants' response on the EI related tasks are measured and assessed in accordance with such objectively right answer that measurement and assessment of the EI capabilities through the ability model does not include any bias or exaggerated evaluation of emotional capabilities. 
However, measurement and assessment in the ability model are tough, not easy to administer due to the fact that expert panelists are needed to assess which respond is true, make decision about what respond is right according to objective rules. ${ }^{14}$ There are several instruments aiming to measure the EI related skills through the ability model and performance based tasks. Salovey ${ }^{1}$ developed four branch of the EI, and devised the Multi Factor Emotional Intelligence Scale (MEIS). However, it was not found satisfactory in terms of validity and reliability. Mayer et al., ${ }^{1}$ developed the Mayer Salovey Caruso Emotional Intelligence Test (MSCEIT) to attenuate lengthy MEIS and ameliorate psychometric properties of the MEIS. Construct validation of the MSCEIT via confirmatory factor analysis by Rossen, Kranzler revealed that the MSCEIT does not cover all constructs developed by Mayer et al., ${ }^{1}$ although Mayer et al., ${ }^{1}$ founded that the MSCEIT has good model fit indices. Furthermore, Fan, Jackson, Tang, \& Zhang (2010) suggested that three factor solution of the MSCEIT has the best fitting model (in press) designed the MSCEIT Youth Version for children and youth between the ages 10 and 18 years ${ }^{15}$ investigated the MSCEIT-YV's construct validity and criterion-related related validity and concluded that it is a valid instrument in measuring emotional intelligence based on the ability model. Similarly, Rivers, Brackett, Reyes, Mayer, Caruso, \& Salovey found that the MCEIT-YV produces valid results in measuring emotional intelligence among children aged from 10 to 13. Emotional Intelligence Scale for Children (EISC) was developed by Sullivan through the ability model. However, internal consistency between subscales of the EISC varied low to moderate. Freudenthaler and Neubauer Emotional Intelligence Performance Test is another instrument use to assess emotional intelligence through performance-based approach and the ability model in EI. ${ }^{16}$

Emotional Accuracy Research Scale was developed by Mayer and Geher ${ }^{17}$ in accordance with the ability model. Both of the scales do not have any child or adolescent form. The mixed models make emotions quantifiable through self-report. Self-assessment of emotions assumes that participants are competent enough to evaluate how much they have quality in emotions or their behaviors about the EI skills. In contrast to the ability model and performance based assessment, selfreport of emotional responds may not have any objective criteria. Therefore, it is easy to administer and evaluate. There are numerous scales measuring the EI via self-report. Emotional Quotient Inventory developed by is a self-report inventory with 133 items. Bar-On ${ }^{7}$ devised its youth version that measures the EI of children adolescents who are aged between 7 and 18 years. Another seminal measurement instrument of the EI is Trait Emotional Intelligence Questionnaire (TEIQue) developed by Petrides ${ }^{13}$ adapted it to child and adolescent characteristics by shortening its length and named as Trait Emotional Intelligence Questionnaire- Adolescent Short Form (TEIQue-ASF). The TEIQue-ASF consists of 30 items, two for each of the 15 facets of Trait Emotional Intelligence and measures global trait EI. Its internal consistency reliability coefficient was found as 0.84 . In addition to that, Cooper and Petrides (2010) tested its psychometric construction by using item-response theory and found that TEIQue-ASF has good psychometric properties. However, the fact that the TEIQue and TEIQue-ASF consist of too broad definitions and sub-dimensions, has drawn considerable criticism. ${ }^{18}$

In this present study, an emotional intelligence scale, which measures emotional intelligence through self-report and are originated from Goleman ${ }^{2}$ conceptualization. Measuring emotional intelligence via self-report assumes that participants in the sample have an insight about their social and emotional skill in depth and are objective, consistent, and genuine in assessing those skills. Age of 10 is a period in which metacognitive awareness, abstract reasoning, and objective thinking without being impressed with events, and objects begin to emerge among children. Moreover, Gender differences are clear between early childhood and age of 8 in favor of female children with respect to emotional intelligence skills. However, this difference disappears between 10 to 12 years because of more increase in male children's emotional intelligences. ${ }^{19}$ Therefore, during primary school process; age of 10 is a period in which both female and male children are equal in terms of emotional intelligence skills. When the literature is closely investigated, it can be seen that emotional intelligence scales for children and adolescents were designed in accordance with the Ability Model, the Bar-on Model, the Trait Emotional Intelligence Model but there is no emotional intelligence scale which originated from Goleman's conceptualization of the EI. Therefore, existing scale were grounded on such different models were there is no use in modifying them. Therefore, the present study aims to develop valid and reliable instrument of the EI based on Goleman's conceptualization of the EI. ${ }^{20}$

\section{Methodology}

The aim of the present study is to develop a self-report emotional intelligence for subjects of and above 10 years in age so as to measure and assess level of emotional learning. Item development, content validity, structural validity, reliability, and validity analysis were orderly carried out in the development process. The present study consists of two factor analysis as Exploratory Factor Analysis discovering factor structures, internal consistency coefficients and Confirmatory Factor Analysis which investigates how well data fit into previously revealed factor structures. ${ }^{21}$

\section{Item generation}

The scale development process began with the creation of items to assess a construct under examination. This process was conducted inductively, by generating items first, from which scales were then derived. Experts on the subject were typically asked to provide descriptions of their perception to describe emotional intelligence. Responses were then classified into different categories by content analysis. From these categorized responses, items were then derived. For item development, basic guidelines were followed to ensure that the items are properly constructed. Statements are simple and as short and the familiar language is used to target respondents. ${ }^{22}$

\section{Content adequacy assessment}

The items were pre-tested for content adequacy. Assuring content adequacy prior to final questionnaire development provides support ${ }^{23}$ for construct validity as it allows the deletion of items that may be conceptually inconsistent. Experts in the content domain along with the naive respondents were presented with construct definitions without titles and are asked to match items with a corresponding definition. An acceptable agreement index was determined prior to administration of the items and definitions.

\section{Questionnaire administration}

The retained items were then presented to an appropriate sample with the objective of examining how well those items confirmed expectations regarding the properties of the new measure. ${ }^{24}$ The new items were administered with other established measures to later assess the distinction or overlap among the proposed and existing scales. In addition, data from existing measures was used for preliminary examination of construct and criterion-related validity of the new scale. 


\section{Item scaling}

Likert scales are the most commonly used in survey research using questionnaires. ${ }^{25}$ Likert scales include several "points" along a continuum that define various amounts or levels of the measured attribute or variable (e.g., agreement, frequency, importance etc.).

\section{Sample size}

The data was collected from an adequate sample size to appropriately conduct subsequent analyses. Earlier recommendations for item-to-response ratios ranged from $1: 4^{26-30}$ to at least $1: 10^{31}$ for each set of scales to be factor analyzed. Recent studies have found that in most cases, a sample size of 150 observations should be sufficient to obtain an accurate solution in exploratory factor analysis, as long as item intercorrelations are reasonably strong. ${ }^{32,33}$ For confirmatory factor analysis, we recommend a minimum sample size of 100 (cf.,.). ${ }^{34}$ However, we suggest that a conservative approach be adopted. As the number of items increases, it may be necessary to increase the number of respondents. As sample size increases, (Figure 1) \& (Figure 2) the likelihood of attaining statistical significance increases, which in turn may distort the practical meaning of the results. In this study, a significant sample of 1664 subjects was taken (Figure 3). ${ }^{35-37}$

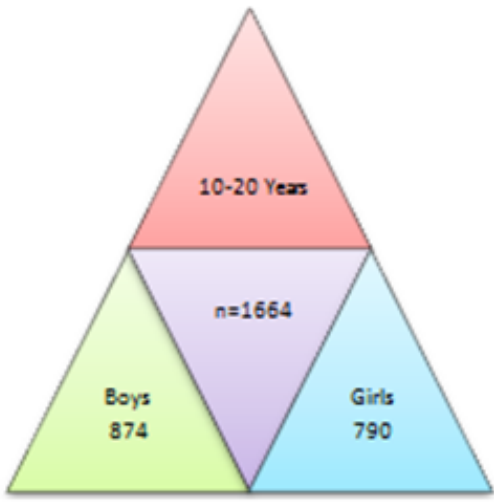

Figure I Sampling.

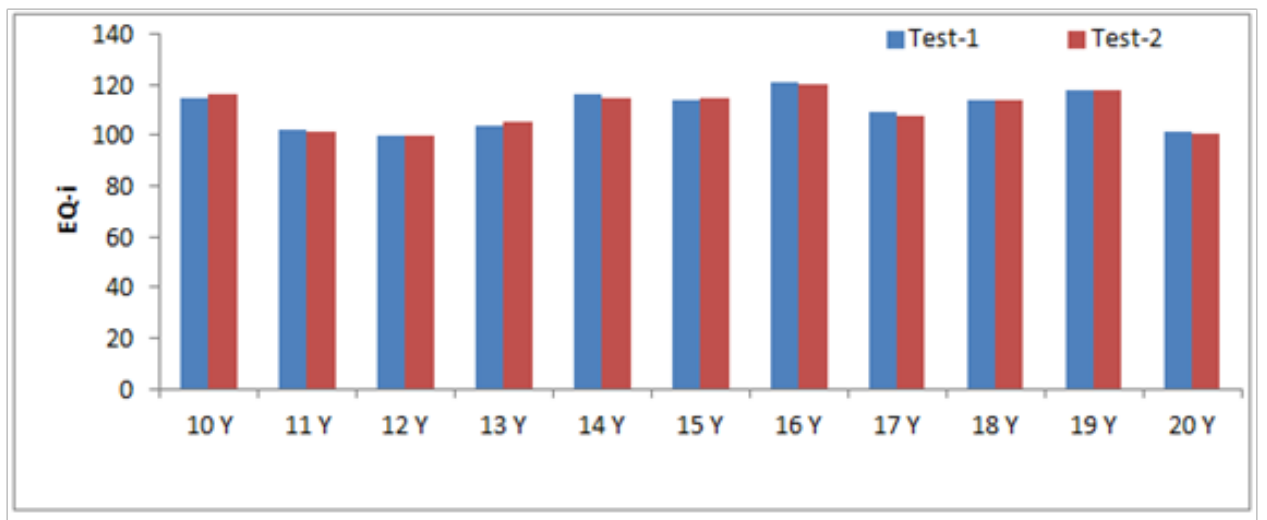

Figure 2 Difference in Mean of female subjects in Test-I and Test-2.

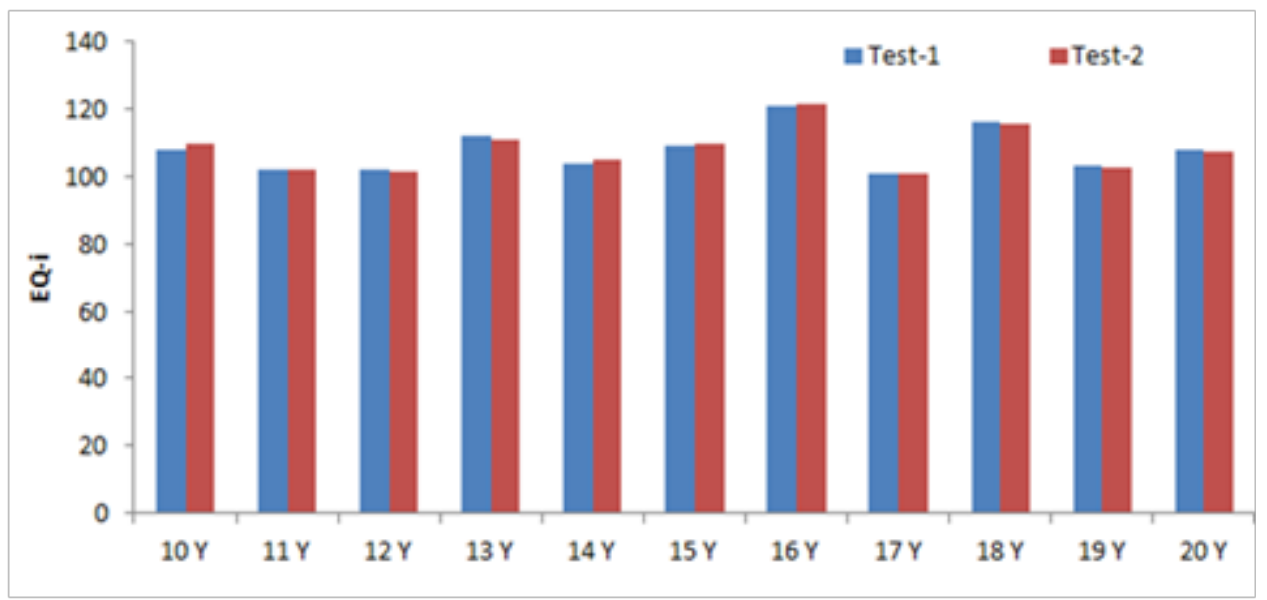

Figure 3 Difference in Mean of male subjects in Test-I and Test-2.

\section{Result and discussion}

\section{Factor analysis}

There are two basic types of factor analyses available for the scale development process. The first is termed exploratory and is commonly used to reduce the set of observed variables to a smaller, more parsimonious set of variables. The second type is called confirmatory and is used to assess the quality of the factor structure by statistically testing the significance of the overall model (e.g., distinction among scales), as well as the relationships among items and scales. As the authors used the inductive approach, exploratory factor analysis was used (Table 1). ${ }^{38,39}$

\section{Internal consistency assessment}

After unidimensionality of each scale has been established. ${ }^{33}$ Reliability was calculated by Cronbach's alpha which tells how well the items measure the same construct (Table 2) \& (Table 3). ${ }^{40-44}$ 
Table I The EQ-i Scales and the factors assessed by them

\begin{tabular}{|c|c|c|c|c|c|c|}
\hline EQ-i Scales & \multicolumn{2}{|c|}{$\begin{array}{l}\text { The El competencies and skills assessed by each } \\
\text { scale }\end{array}$} & Item no & $\begin{array}{l}\text { Value of corrected- } \\
\text { Item correlation }\end{array}$ & Item no & $\begin{array}{l}\text { Value of corrected- } \\
\text { Item correlation }\end{array}$ \\
\hline Intrapersonal & \multicolumn{2}{|c|}{ Self-awareness and self-expression: } & $\mathrm{I}$ & 0.304 & 38 & 0.512 \\
\hline Self-Regard & \multicolumn{2}{|c|}{ To accurately perceive, understand and accept oneself. } & 2 & 0.31 & 39 & 0.245 \\
\hline \multirow{2}{*}{$\begin{array}{l}\text { Emotional Self- } \\
\text { Awareness }\end{array}$} & \multirow{2}{*}{\multicolumn{2}{|c|}{ To be aware of and understand one's emotions. }} & 3 & 0.364 & 40 & 0.36 \\
\hline & & & 4 & 0.356 & $4 I$ & 0.19 \\
\hline \multirow[t]{2}{*}{ Assertiveness } & \multicolumn{2}{|c|}{$\begin{array}{l}\text { To effectively and constructively express one's emotions } \\
\text { and oneself. }\end{array}$} & 5 & 0.361 & 42 & 0.32 \\
\hline & \multirow{2}{*}{\multicolumn{2}{|c|}{$\begin{array}{l}\text { To be self-reliant and free of emotional dependency on } \\
\text { others. }\end{array}$}} & 6 & 0.368 & 43 & 0.22 \\
\hline Independence & & & 7 & 0.315 & 44 & 0.304 \\
\hline \multirow{2}{*}{$\begin{array}{l}\text { Self- } \\
\text { Actualization }\end{array}$} & \multirow{2}{*}{\multicolumn{2}{|c|}{$\begin{array}{l}\text { To strive to achieve personal goals and actualize one's } \\
\text { potential. }\end{array}$}} & 8 & 0.33 & 45 & 0.31 \\
\hline & & & 9 & 0.26 & 46 & 0.364 \\
\hline Interpersonal & \multicolumn{2}{|c|}{ Social awareness and interpersonal relationship: } & 10 & 0.18 & 47 & 0.28 \\
\hline Empathy & \multicolumn{2}{|c|}{ To be aware of and understand how others feel. } & 11 & 0.316 & 48 & 0.329 \\
\hline \multirow[t]{2}{*}{$\begin{array}{l}\text { Social } \\
\text { Responsibility }\end{array}$} & \multirow{2}{*}{\multicolumn{2}{|c|}{$\begin{array}{l}\text { To identify with one's social group and cooperate with } \\
\text { others. }\end{array}$}} & 12 & 0.319 & 49 & 0.29 \\
\hline & & & 13 & 0.318 & 50 & 0.31 \\
\hline $\begin{array}{l}\text { Interpersonal } \\
\text { Relationship }\end{array}$ & \multicolumn{2}{|c|}{$\begin{array}{l}\text { To establish mutually satisfying relationships and relate } \\
\text { well with others. }\end{array}$} & 14 & 0.35 & 51 & 0.23 \\
\hline \multirow{2}{*}{$\begin{array}{l}\text { Stress } \\
\text { Management }\end{array}$} & \multirow{2}{*}{\multicolumn{2}{|c|}{ Emotional management and regulation: }} & 15 & 0.52 & 52 & 0.52 \\
\hline & & & 16 & 0.514 & 53 & 0.56 \\
\hline \multirow[t]{2}{*}{$\begin{array}{l}\text { Stress } \\
\text { Tolerance }\end{array}$} & \multirow{2}{*}{\multicolumn{2}{|c|}{ To effectively and constructively manage emotions. }} & 17 & 0.45 & 54 & 0.48 \\
\hline & & & 18 & 0.24 & 55 & 0.47 \\
\hline $\begin{array}{l}\text { Impulse } \\
\text { Control }\end{array}$ & To effect & and constructively control emotions. & 19 & 0.524 & 56 & 0.345 \\
\hline Adaptability & Change $r$ & agement: & 20 & 0.215 & 57 & 0.37 \\
\hline & To objec & ly validate one's feelings and thinking with & 21 & 0.15 & 58 & 0.35 \\
\hline Realıty- lestıng & external & lity. & 22 & 0.52 & 59 & 0.33 \\
\hline Flexibility & $\begin{array}{l}\text { To adapt } \\
\text { situation }\end{array}$ & adjust one's feelings and thinking to new & 23 & 0.56 & 60 & 0.31 \\
\hline & & & 24 & 0.48 & 61 & 0.51 \\
\hline $\begin{array}{l}\text { Problem- } \\
\text { Solving }\end{array}$ & $\begin{array}{l}\text { To effect } \\
\text { interpers }\end{array}$ & $\begin{array}{l}\text { solve problems of a personal and } \\
\text { nature. }\end{array}$ & 25 & 0.47 & 62 & 0.31 \\
\hline General Mood & Self-moti & on: & 26 & 0.345 & 63 & 0.4 \\
\hline Optimism & To be po & e and look at the brighter side of life. & 27 & 0.63 & 64 & 0.38 \\
\hline Happiness & To feel cc & ent with oneself, others and life in general. & 28 & 0.35 & 65 & 0.36 \\
\hline Table 2 EQ Sco & and thei & ference & 29 & 0.336 & 66 & 0.34 \\
\hline & & & 30 & 0.35 & 67 & 0.64 \\
\hline & Scores & Inference & 31 & 0.58 & 68 & 0.6 \\
\hline & & Below Par & 32 & 0.25 & 69 & 0.56 \\
\hline & & Below Average & 33 & 0.304 & 70 & 0.52 \\
\hline & 110 & Average & 34 & 0.31 & 71 & 0.35 \\
\hline & -120 & Above Average (Good) & 35 & 0.364 & 72 & 0.32 \\
\hline & -140 & Very Good & 36 & $0.4 I$ & & \\
\hline & ove 140 & Excellent & 37 & 0.51 & & \\
\hline
\end{tabular}

Table 3 Value of Corrected-Item Correlation 


\section{Construct validation}

At this point, the new scale demonstrated content validity and internal consistency reliability, both of which provided supportive evidence of construct validity. Further evidence of construct validity was accomplished by examining the extent to which the scales correlated with other measures designed to assess similar constructs (convergent validity) and to which they do not correlate with dissimilar measures $^{45}$ (discriminant validity) (Table 4) \& (Table 5).

Table 4 Discarded item list

\begin{tabular}{l} 
Item No \\
\hline $9,10,18,20,21,32,39,41,43,47,49,51$
\end{tabular}

Table 5 Retained item list

\begin{tabular}{|c|c|c|c|}
\hline Item No & $\begin{array}{l}\text { Value of Corrected- } \\
\text { Item Correlation }\end{array}$ & Item No & $\begin{array}{l}\text { Value of Corrected- } \\
\text { Item Correlation }\end{array}$ \\
\hline I & 0.304 & 46 & 0.364 \\
\hline 2 & 0.31 & 48 & 0.329 \\
\hline 3 & 0.364 & 50 & 0.31 \\
\hline 4 & 0.356 & 52 & 0.52 \\
\hline 5 & 0.361 & 53 & 0.56 \\
\hline 6 & 0.368 & 54 & 0.48 \\
\hline 7 & 0.315 & 55 & 0.47 \\
\hline 8 & 0.33 & 56 & 0.345 \\
\hline II & 0.316 & 57 & 0.37 \\
\hline 12 & 0.319 & 58 & 0.35 \\
\hline 13 & 0.318 & 59 & 0.33 \\
\hline 14 & 0.35 & 60 & 0.31 \\
\hline 15 & 0.52 & 61 & 0.51 \\
\hline 16 & 0.514 & 62 & 0.31 \\
\hline 17 & 0.45 & 63 & 0.4 \\
\hline 19 & 0.524 & 64 & 0.38 \\
\hline 22 & 0.52 & 65 & 0.36 \\
\hline 23 & 0.56 & 66 & 0.34 \\
\hline 24 & 0.48 & 67 & 0.64 \\
\hline 25 & 0.47 & 68 & 0.6 \\
\hline 26 & 0.345 & 69 & 0.56 \\
\hline 27 & 0.63 & 70 & 0.52 \\
\hline 28 & 0.35 & 71 & 0.35 \\
\hline 29 & 0.336 & 72 & 0.32 \\
\hline 30 & 0.35 & & \\
\hline 31 & 0.58 & & \\
\hline 33 & 0.304 & & \\
\hline 34 & 0.31 & & \\
\hline 35 & 0.364 & & \\
\hline 36 & 0.41 & & \\
\hline 37 & 0.51 & & \\
\hline 38 & 0.512 & & \\
\hline 40 & 0.36 & & \\
\hline
\end{tabular}

\section{Replication}

It was then necessary to collect another set of data from an appropriate sample and repeat the scale-testing process with the new scales. The data from sources other than the respondent, such as performance appraisals, peers were collected. These analyses ensured the researcher with the confidence that the finalized measures possess reliability and validity and would be suitable for use in future research. Cronbach's Alpha has been taken as a measure of reliability. It was decided that a scale with an Alpha reliability of 0.70 or more would be considered adequate reliability. ${ }^{46}$ This is conventionally accepted as a thumb rule for reliability. It was also decided that item must have a minimum of 0.30 items to total correlation. To ascertain face validity and content validity it was decided that at least six psychologists and educationists agreed that item on face value belonged to the dimension that it aimed to measure concurrent validity. It was also addressed by having scores of respondents on certain criterion variables. This scale has sufficient level of reliability and validity. The authors has reported the value of internal reliability $(\mathrm{a}=0.88)$, and content and face validity is examined by asking from 10 specialists (Table 6) \& (Table 7). ${ }^{47-55}$

Table 6 Difference in Mean, SD and SEM of male subjects in Test-I and Test-2

\begin{tabular}{|c|c|c|c|c|c|}
\hline Test & Mean & SD & SEM & T-Test & Level of Sig \\
\hline Test-I & 108 & 5.21 & 2.35 & $13.0 \mid$ & NS \\
\hline Test-2 & 109.6 & 5.2 & 2.15 & & \\
\hline Test-I & 102 & 8.99 & 1.37 & 11.49 & NS \\
\hline Test-2 & 102 & 8.15 & 1.15 & & \\
\hline Test-I & 102 & 10.02 & 1.83 & 9.67 & NS \\
\hline Test-2 & 101.6 & 10.1 & 0.35 & & \\
\hline Test-I & 112 & 6.4 & 0.13 & 13.17 & NS \\
\hline Test-2 & 110.9 & 6.45 & 0.15 & & \\
\hline Test-I & 104 & 8.17 & 0.95 & 15.82 & NS \\
\hline Test-2 & 105.1 & 8.07 & 0.96 & & \\
\hline Test-I & 109 & 11.76 & 0.45 & 9.75 & NS \\
\hline Test-2 & 109.6 & 10.86 & 0.54 & & \\
\hline Test-I & $|2|$ & 6.69 & 2.54 & 14.64 & NS \\
\hline Test-2 & 121.4 & 7.15 & 2.65 & & \\
\hline Test-I & 101 & 10.33 & 1.84 & 12.5 & NS \\
\hline Test-2 & 100.96 & 11.15 & 1.86 & & \\
\hline Test-I & 116 & 8.14 & 1.42 & 7.22 & NS \\
\hline Test-2 & 115.8 & 7.96 & 1.44 & & \\
\hline Test-I & 103 & 9 & 2.06 & 8.08 & NS \\
\hline Test-2 & 102.8 & 10.01 & 2.05 & & \\
\hline Test-I & 108 & 9.89 & 2.59 & 15.18 & NS \\
\hline Test-2 & 107.5 & 9.76 & 2.49 & & \\
\hline
\end{tabular}


Table 7 Difference in Mean, SD and SEM of female subjects in Test-I and Test-2

\begin{tabular}{|c|c|c|c|c|c|c|}
\hline Test & & Mean & SD & SEM & T-Test & Level of sig \\
\hline \multirow[t]{2}{*}{10 Years } & Test-I & 115 & 5.43 & 0.82 & $16.7 \mid$ & NS \\
\hline & Test-2 & 116.5 & 5.12 & 0.8 & & \\
\hline \multirow[t]{2}{*}{ II Years } & Test-I & 102 & II & 0.3 & 16.56 & NS \\
\hline & Test-2 & I.I & 10.56 & 0.24 & & \\
\hline \multirow[t]{2}{*}{12 Years } & Test-I & 100 & 11.9 & 2.54 & 13.77 & NS \\
\hline & Test-2 & 99.5 & 10.69 & 2.15 & & \\
\hline \multirow[t]{2}{*}{13 Years } & Test-I & 104 & 9.67 & 1.71 & 11.28 & NS \\
\hline & Test-2 & 104.9 & 9.56 & 1.05 & & \\
\hline \multirow[t]{2}{*}{14 Years } & Test-I & 116 & 10.09 & 1.63 & 9.59 & NS \\
\hline & Test-2 & 115 & 10 & 101 & & \\
\hline \multirow[t]{2}{*}{15 Years } & Test-I & 114 & 4.92 & 1.06 & 9.34 & NS \\
\hline & Test-2 & 114.6 & 4.56 & 0.65 & & \\
\hline \multirow[t]{2}{*}{16 Years } & Test-I & 121 & 10.47 & 0.98 & 9.8 & NS \\
\hline & Test-2 & 119.86 & 10.58 & 0.26 & & \\
\hline \multirow[t]{2}{*}{ I7Years } & Test-I & 109 & 5.02 & 1.96 & 15.24 & NS \\
\hline & Test-2 & 108 & 5 & 1.9 & & \\
\hline \multirow[t]{2}{*}{18 Years } & Test-I & 114 & 7.78 & 0.99 & 11.99 & NS \\
\hline & Test-2 & 114.2 & 8 & 0.86 & & \\
\hline \multirow[t]{2}{*}{19 Years } & Test-I & 118 & 5.37 & 0.59 & 15.93 & NS \\
\hline & Test-2 & 117.5 & 6.1 & 0.45 & & \\
\hline \multirow[t]{2}{*}{20 Years } & Test-I & 101 & 4.48 & 1.64 & 12.33 & NS \\
\hline & Test-2 & 100.56 & 5.2 & 1.66 & & \\
\hline
\end{tabular}

\section{Conclusion}

Shelling the nut, Results indicated that the scale is reliable and valid instrument in measuring emotional intelligence. Construct validity was supplemented by finding its relationship with peer rating and correlation was found to be moderately positive. The Scale is a promising measure with good items homogeneity, internal consistency and a meaningful pattern of validity. In recapitulation, the study came out with significant results as the correlation coefficient was found to be significantly high witnessing the high reliability and validity of the test.

\section{Acknowledgements}

Authors express indebtedness to the Almighty, who is the apostle of strength. Genuine thanks are expressed to all the authors/ researches whose work is referred for making the present study a real success. Immense thanks are expressed to the subjects and their parents who had reportedly facilitated the research process. Authors are inevitably grateful to all those directly as well as indirectly involved in the auspicious research work.

\section{Conflict of interest}

The auhtor declares there is no conflict of interest.

\section{References}

1. Salovey P, Mayer JD. Emotional intelligence. Imagination, Cognition, and Personality. 1990;9:185-211.

2. Goleman D. Working with emotional intelligence. New York: Bantam Books. 1989. p. 1-7.

3. Anastasi A. Psychological testing $6^{\text {th }}$ edition. New York: Macmillan Publishing. 1988

4. Appelbaum SA. Psychological mindedness: Word, concept, and essence. International Journal of Psycho-Analysis. 1973;54(1):35-46.

5. Bagozzi RP, Yi Y, Phillips LW. Assessing construct validity in organizational research. Administrative Science Quarterly. 1991;36:421458

6. Bar-On R. The Bar-On Emotional Quotient Inventory (EQ-i): Rationale, description, and summary of psychometric properties. In Glenn Geher editor. Measuring emotional intelligence: Common ground and controversy. Hauppauge, NY: Nova Science Publishers. 2004. p. 111142

7. Bar-On R, Fund S. The impact of emotional and social intelligence on self-perceived physical health. Unpublished manuscript. 2004.

8. Bar-On R, Parker JDA. The Bar-On Emotional Quotient Inventory: Youth Version (EQ-i:YV) Technical Manual. Toronto, Canada: MultiHealth Systems, Inc. 2000.

9. Bechara A, Tranel D, Damasio R. Poor judgment in spite of high intellect: Neurological evidence for emotional intelligence. In R BarOn et al. editors. Handbook of emotional intelligence. San Francisco: Jossey-Bass. 2000

10. Bem DJ, Allen A. On predicting some of the people some of the time: The search for cross-situational consistencies in behavior. Psychological Review. 1974;81(6):506-520

11. Matthews G, Roberts RD, Zeidner M. Development of emotional intelligence: A skeptical - but not dismissive - perspective. Human Development. 2003;46:109-114.

12. Bollen KA. Structural equations with latent variables. New York: John Wiley \& Sons, Inc. Bums JM editor. (1978). Leadership. New York: Harper and Row. 1989.

13. Petrides KV, Furnham A. On the dimensional structure of emotional intelligence. Personality and Individual Differences. 2002;29:313-320.

14. Boyatzis RE, Sala F. The Emotional Competency Inventory (ECI). In Glenn Geher editor. Measuring emotional intelligence: Common ground and controversy. Hauppauge, NY: Nova Science Publishers. 2004.

15. Boyatzis RE, Goleman D, HayGroup. The Emotional Competence Inventory (ECI). Boston: HayGroup. 2001.

16. Brackett MA, Salovey P. Measuring emotional intelligence with the Mayer-Salovey-Caruso Emotional Intelligence Test (MSCEIT). In Glenn Geher editor. Measuring emotional intelligence: Common ground and controversy. Hauppauge, NY: Nova Science Publishers. 2004.

17. Geher G. Measuring emotional intelligence: Common ground and controversy. Hauppauge, NY: Nova Science Publishers. 2004.

18. Campbell DT, Fiske DW. Convergent and discriminant validation by the multitrait-multimethod matrix. Psychological Bulletin. 1959;56:81-105.

19. Carmines EG, Mclver J. Analyzing models with unobserved variables: Analysis of covariance structures. In G Bohmstedt et al. editors. Social measurement: Current issues. Beverly Hills: Sage. 1981.

20. Cattell RB, Eber HW, Tatsuoka MM. Handbook for the Sixteen Personality Factor Questionnaire (16PF). Champaign, Illinois: Institute for Personality and Ability Testing. 1970. 
21. Chapin FS. Preliminary standardization of a social impact scale. American Sociological Review. 1942;7:214-225.

22. Churchill GA. A paradigm for developing better measures of marketing constructs. 1979. p. 64-73.

23. Cohen J. Statistical power analysis for the behavioral sciences. New York: Academic. 1969. p. 1-579.

24. Cook JD, Hepworth SJ, Wail TD. The experience of work. San Diego: Academic Press. 1981

25. Darwin C. The expression of the emotions in man and animals. Chicago: University of Chicago Press. 1965

26. Davies M, Stankov L, Roberts RD. Emotional intelligence: In search of an elusive construct. Journal of Personality and Social Psychology. 1988;75(4):989-1015.

27. Doll EA. A generic scale of social maturity. American Journal of Orthopsychiatry. 1935;5(2):180-188

28. Duncan J. An adaptive coding model of neural function in the prefrontal cortex. Nature Reviews Neuroscience. 2001;2:820-829.

29. Dunkley J. The psychological well-being of coronary heart disease patients before and after an intervention program. Unpublished master's thesis. University of Pretoria, South Africa. 1996.

30. Ford JK, MacCallum RC, Tait M. The application of exploratory factor analysis in applied psychology: A critical review and analysis. Personnel Psychology. 1986;39:291-314.

31. Freedman J. Key lessons from 35 years of social-emotional education How Self-Science builds self-awareness, positive relationships, and healthy decision-making. Perspectives in Education. 2003;21(4):69-80.

32. Gardner H. Frames of mind. New York: Basic Books. 1983.

33. Gerbing DW, Anderson JC. An updated paradigm for scale development incorporating unidimensionality and its assessment. Journal of Marketing Research. 1988. p. 186-192.

34. Handley R. AFRS rates emotional intelligence. Air Force Recruiter News. 1997.

35. Hater JJ. Bass BM. Superior's evaluations and subordinates' perceptions of transformational and transactional leadership. Journal of Applied Psychology. 1988;73(4):695-702.

36. Hedlund J, Sternberg RJ. Too many intelligence's? Integrating social, emotional, and practical intelligence. In R Bar-On et al., editors. The Handbook of Emotional Intelligence. San Francisco: Jossey-Bass. 1900

37. Hunter JE, Hunter RF. Validity and utility of alternative predictors of job performance. Psychological Bulletin. 1984;76(1):72-93.

38. Kaplan HI, Sadock BJ. Synopsis of Psychiatry $6^{\text {th }}$ edition. Baltimore, MD: Williams \& Wilkins. 1991.

39. Krivoy E, Weyl Ben-Arush M, Bar-On R. Comparing the emotional intelligence of adolescent cancer survivors with a matched sample from the normative population. Medical \& Pediatric Oncology. 2000;35(3):382.
40. Lane RD. Levels of emotional awareness: Neurological, psychological and social perspectives. In $\mathrm{R}$ Bar-On et al., editors. Handbook of emotional intelligence. San Francisco: Jossey-Bass. 2000.

41. Lane RD, Schwartz GE. Levels of emotional awareness: A cognitivedevelopmental theory and its application to psychopathology. American Journal of Psychiatry. 1987;144(2):133-143.

42. MacLean PD. Psychosomatic disease and the visceral brain: Recent developments bearing on the Papez theory of emotion. Psychosomatic Medicine. 1949;11338-353.

43. Mayer JD, Salovey P, Caruso DR. Mayer-Salovey-Caruso Emotional Intelligence Test (MSCEIT). Toronto, Canada: Multi-Health Systems, Inc. 2002.

44. Moss FA, Hunt T, Omwake KT. Social intelligence test. Washington, DC: Center for Psychological Service. 1927.

45. Parker JDA, Creque RE, Barnhart DL, et al. Academic achievement in high school: Does emotional intelligence matter? Personality and Individual Differences. 2004;37:1321-1330.

46. Plake BS, Impara JC. Supplement to the thirteenth mental measurement yearbook. Lincoln, NE: Buros Institute for Mental Measurement. Press. 1999.

47. Ruderman M, Bar -On R. The impact of emotional intelligence on leadership. 2003.

48. Ruesch J. The infantile personality; the core problem of psychosomatic medicine. Psychosomatic Medicine. 1948;10:134-144.

49. Saarni C. Emotional competence: How emotions and relationships become integrated. Nebr Symp Motiv. 1990;36:115-182.

50. Shadbolt B, Barresi J, Craft P. Self-rated health as a predictor of survival among patients with advanced cancer. Journal of Clinical Oncology. 2002;20(10):2514-2519.

51. Shostrom EL. Personal Orientation Inventory: An Inventory for the Measurement of Self-Actualization. San Diego, CA: Educational Industrial Testing Service. 1974.

52. Sifneos PE. Clinical observations on some patients suffering from a variety of psychosomatic diseases. Acta Medicina Psychosomatica. 1967;21:133-136.

53. Stone-McCown K, Jensen AL, Freedman JM. Self science: The emotional intelligence curriculum. San Mateo, CA: Six Seconds. 1998.

54. Van Rooy DL, Viswesvaran C. Emotional intelligence: A meta-analytic investigation of predictive validity and nomological net. Journal of Vocational Behavior. 2004;65(1):71-95.

55. Van Rooy DL, Pluta P, Viswesvaran C. An evaluation of construct validity: What is this thing called emotional intelligence. Manuscript submitted for publication. 2004. 